\title{
Reparo de lesão penetrante em parede torácica de cão, ocasionada por javali (Sus scrofa scrofa), com flape unipediculado de músculo reto abdominal
}

\author{
[Unipediculated flap of muscle rectos abdominales to repair a penetrating injury caused by javali \\ (Sus scrofa scrofa) on the thoracic wall of a dog] \\ M.T. Linhares ${ }^{1}$, Í.B. Freitas ${ }^{2}$, R. Gorczak ${ }^{3}$, J.P.S. Feranti ${ }^{1}$, R.M. Zanetti ${ }^{4}$, \\ M. Macagnan ${ }^{5}$ J.E.W. Schossler ${ }^{6}$, M.V. Brun ${ }^{6,7}$ \\ ${ }^{1}$ Aluno de pós-graduação - Universidade Federal de Santa Maria - UFSM - Santa Maria, RS \\ ${ }^{2}$ Aluno de pós-graduação - Universidade Federal do Paraná - UFPR - Curitiba, PR \\ ${ }^{3}$ Aluna de pós-graduação - Universidade Federal do Pampa - Unipampa - Santana do Livramento, RS \\ ${ }^{4}$ Residente - Universidade Federal de Santa Maria - UFSM - Santa Maria, RS \\ ${ }^{5}$ Médico veterinário autônomo \\ ${ }^{6}$ Universidade Federal de Santa Maria - UFSM - Santa Maria, RS \\ ${ }^{7}$ Bolsista de produtividade do CNPq
}

\begin{abstract}
RESUMO
Lesões penetrantes no tórax causadas por interação animal são frequentes em cães e caracterizam-se por dano extenso e desvitalização dos tecidos moles adjacentes. Quando a musculatura local é insuficiente para a reconstrução, retalhos musculares podem ser mobilizados para reparar o defeito torácico. $\mathrm{O}$ presente relato tem como objetivo demonstrar uma alternativa para o reparo de defeito da parede torácica em um cão, ocasionada por interação com javali (Sus scrofa scrofa), utilizando flape unipediculado de músculo reto abdominal. Com base na literatura consultada, essa técnica reconstrutiva ainda não foi descrita. O flape de músculo reto abdominal mostrou-se uma alternativa viável no reparo de lesão extensa e infectada na parede torácica em cães.
\end{abstract}

Palavras-chave: flape muscular, tórax, cirurgia reconstrutiva, canino

\begin{abstract}
Penetrating thoracic wounds caused by animal bites are common in dogs and are characterized by extensive trauma and adjacent soft tissue devitalization. When the local musculature is insufficient for the reconstruction, muscle flaps can be taken to repair the thoracic defect. The aim of the present report is to demonstrate an alternative to the thoracic wall defect repair in a dog which was attacked by javali (Sus scrofa scrofa), using unipediculated flap of the rectus abdominis muscle. Based on the literature, this reconstructive technique has not yet been described. The rectus abdominis muscle flap proves to be a useful alternative for the repair of extensive and infected thoracic wall lesion in dogs.
\end{abstract}

Keywords: muscle flap, chest, reconstructive surgery, canine

\section{INTRODUÇÃO}

Lesões à parede torácica decorrentes de interação animal são frequentes em cães (Shahar et al., 1997) e podem resultar em extensa desvitalização dos tecidos moles subjacentes (Orton, 2007). A exploração cirúrgica dessas feridas objetiva restabelecer a integridade do espaço pleural (Hunt, 2012) e desbridar

Recebido em 28 de abril de 2015

Aceito em 15 de novembro de 2015

* Autor para correspondência (corresponding author)

E-mail: mauriciovelosobrun@hotmail.com completamente todos os tecidos desvitalizados, a fim de evitar ou controlar infecções (Shahar et al., 1997; Scheepens et al., 2006).

Quando o desbridamento resulta em extensos defeitos de tecidos moles e o tecido muscular restante é insuficiente para permitir a sutura primária, retalhos musculares e flapes do omento maior podem ser utilizados para vedar os espaços 
intercostais e ocluir a ferida (Orton, 2007; Hunt, 2012).

Segundo Kulahci et al. (2011) e Tukiainen (2013), os retalhos pediculados musculares, ou musculocutâneos regionais, são a primeira escolha para o reparo de defeitos da parede torácica em humanos. Os principais flapes musculares selecionados para a reconstrução de defeitos da parede torácica em humanos baseiam-se nos músculos grande dorsal, reto abdominal, peitoral, serrátil e oblíquo abdominal externo (Skoracki e Chang, 2006; Tukiainen, 2013). Músculos recrutados como flapes para ocluir defeitos da parede torácica de pequenos animais incluem o grande dorsal, o oblíquo abdominal externo, o transverso abdominal e o diafragma (Orton, 2007; Hunt, 2012).

O músculo reto abdominal tem sido amplamente utilizado na cirurgia reconstrutiva humana, por tratar-se de um retalho muscular versátil, resistente e com um grande arco de rotação (Kulahci et al., 2011). Em cães, o retalho do músculo reto abdominal foi usado com sucesso para reconstruir defeitos da uretra, da vesícula urinária, da extremidade distal de membros e da cavidade oral (Miller et al., 2007), na correção de hérnia pré-púbica (Archipow e Lanz, 2011) e na correção de defeitos diafragmáticos (Faria et al., 2000).

O presente relato descreve o reparo de uma lesão torácica penetrante em um cão, complicada por extensa desvitalização tecidual e infecção, com o uso de um flape unipediculado de músculo reto abdominal. De acordo com o conhecimento dos autores, essa técnica reconstrutiva ainda não havia sido descrita para o reparo de defeitos na parede torácica de pequenos animais.

\section{RELATO DE CASO}

Um canino, macho, sem raça definida, com cinco anos de idade, pesando $25,6 \mathrm{~kg}$, foi atendido no Hospital Veterinário Universitário da Universidade Federal de Santa Maria, apresentando pneumotórax aberto, deiscência e sinais de infecção em lesão penetrante na parede torácica esquerda, previamente submetida à síntese. Essa ferida foi ocasionada por um acidente com um javali (Sus scrofa scrofa) e foi cirurgicamente reduzida no mesmo dia. Três dias após, houve deiscência, e o paciente foi encaminhado para atendimento hospitalar.

Ao exame clínico, constatou-se padrão respiratório taquipneico, mucosa rosa-pálida, tempo de reperfusão capilar de dois segundos, frequência cardíaca de 120 batimentos por minuto e temperatura retal de $38,5^{\circ} \mathrm{C}$. O paciente foi submetido a exame radiográfico da região torácica, onde foi observada radiolucência em hemitórax esquerdo e deslocamento da silhueta cardíaca para o lado direito, indicando pneumotórax, sem evidência de alterações nas demais estruturas intratorácicas.

Foram coletadas amostras de sangue para avaliação de hemograma e bioquímica sérica. Observou-se anemia microcítica-normocrômica $(\mathrm{HT}=25,5 \%$, hemoglobina $=8,7 \mathrm{~g} / \mathrm{dL}$, hemácias $=$ $4,39 / \mu \mathrm{L}, \mathrm{VCM}=58,2 \mathrm{fL}, \mathrm{CHCM}=34,1 \%$ ), e leucocitose (18.700 leucócitos totais/ $\mu \mathrm{L})$ com desvio à esquerda. Na avaliação bioquímica, observou-se hipoalbuminemia $(0,60 \mathrm{~g} / \mathrm{dL})$ e elevação da creatinina $(1,7 \mathrm{mg} / \mathrm{dL})$.

O paciente foi submetido à toracotomia intercostal, através da ferida torácica existente no dia do atendimento, realizando-se inspeção e irrigação da cavidade pleural, posicionamento de dreno torácico e desbridamento de tecidos desvitalizados. Não foram observadas lesões penetrantes em órgãos intratorácicos. Após dois dias, houve deiscência da ferida e necessidade de reintervenção cirúrgica para desbridamento tecidual adicional, resultando em ressecção de grandes porções da musculatura local.

O paciente permaneceu em internação hospitalar com a prescrição de tramadol $(5 \mathrm{mg} / \mathrm{kg}$, s.c., t.i.d.), dipirona (25mg/kg, i.v., t.i.d.), metronidazol $(15 \mathrm{mg} / \mathrm{kg}$, i.v., b.i.d.) e ceftriaxona $(30 \mathrm{mg} / \mathrm{kg}$, i.v., b.i.d.), fluidoterapia com ringer lactato $(60 \mathrm{~mL} / \mathrm{kg} / 24$ horas), limpeza das feridas cirúrgicas com compressas estéreis e solução de clorexidine $0,05 \%$, bem como drenagem do tórax a cada quatro horas, com uso de uma seringa de $20 \mathrm{~mL}$ acoplada ao dreno torácico até a remoção completa da efusão torácica presente. Dois dias após esse último procedimento cirúrgico, o paciente apresentou extravasamento e acúmulo de líquido correspondente à efusão pleural para o subcutâneo (Fig. 1A), evidenciando a deiscência da sutura muscular. Demonstrou ainda dispneia e drenagem de maiores volumes de efusão torácica 
piosanguinolenta (700mL, a cada 24 horas), sendo submetido à quarta intervenção cirúrgica.

O paciente foi, então, pré-oxigenado por 10 minutos e induzido com isoflurano ao efeito por meio de máscara facial. Para analgesia, foram realizados bolus de morfina $(0,6 \mathrm{mg} / \mathrm{kg}$, i.m.), lidocaína $(1,5 \mathrm{mg} / \mathrm{kg}$, i.v.) e cetamina $(1 \mathrm{mg} / \mathrm{kg}$, i.v.), permanecendo sob infusão contínua de MLK (morfina 3,3 $\mu \mathrm{g} / \mathrm{kg} / \mathrm{min}$; lidocaína $50 \mu \mathrm{g} / \mathrm{kg} / \mathrm{min}$ e cetamina $10 \mu \mathrm{g} / \mathrm{kg} / \mathrm{min}$ ). Foi mantido em plano anestésico cirúrgico com isoflurano, vaporizado em oxigênio $100 \%$ ao efeito, em circuito semifechado.

Com o paciente posicionado em decúbito lateral direito, fez-se uma incisão paralela às costelas, no sexto espaço intercostal, que se estendeu da junção costovertebral ao esterno, observando-se deiscência e extensa desvitalização tecidual (Fig.1B). Removeram-se os tecidos alterados, resultando na ressecção de grande parte da musculatura local. Dada à produção de efusão piosanguinolenta e sendo constatado o quadro de pleurite, foi realizada lavagem do tórax com 10 litros de solução salina estéril. Um dreno torácico $14 \mathrm{Fr}$ foi posicionado no oitavo espaço intercostal, e as costelas foram aproximadas por suturas circuncostais interrompidas, com fio cirúrgico náilon 1.

Preparou-se um flape unipediculado de músculo reto abdominal (Fig. 1C), o qual foi desinserido de sua origem no púbis, a fim de manter íntegros o folheto interno e a fáscia transversa, rotacionado e suturado à musculatura torácica viável em pontos interrompidos simples, com fio cirúrgico náilon 2-0 (Fig. 1D). Dois drenos de sucção contínua, confeccionados com sonda uretral fenestrada $6 \mathrm{Fr}$, foram posicionados durante a síntese de tecido subcutâneo e fixados com sutura em sapatilha com fio cirúrgico náilon 3-0. A síntese de tecido subcutâneo foi realizada em pontos interrompidos simples, com fio cirúrgico náilon 2-0, e a sutura cutânea foi realizada em padrão Wolff, com fio cirúrgico náilon 3-0.

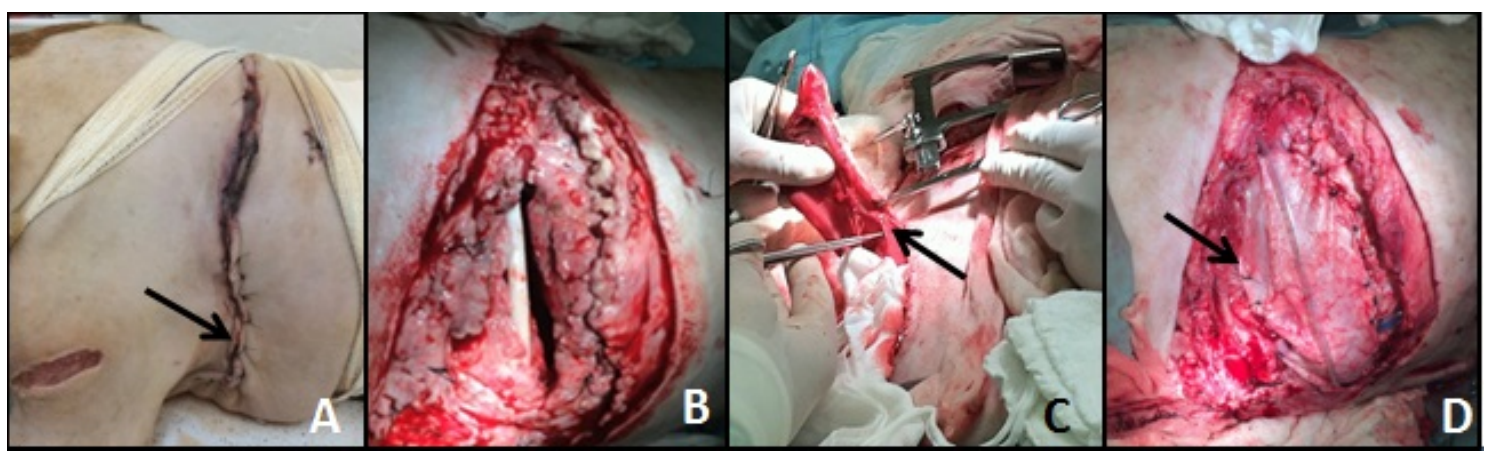

Figura 1. (A) Imagem fotográfica pré-operatória da parede torácica do cão, apontando acúmulo de líquido no subcutâneo (seta), correspondente à efusão pleural (B) Imagem fotográfica transoperatória da ferida, mostrando deiscência na camada muscular e extensa desvitalização tecidual. (C) Imagem fotográfica transoperatória, mostrando a secção do músculo reto abdominal (seta) como parte do preparo do flape unipediculado. (D) Imagem fotográfica do flape de músculo reto abdominal suturado à parede muscular (seta), reparando a lesão torácica após desbridamento.

No pós-operatório imediato, o tórax foi drenado a cada três horas, e, dada à produção de efusão pleural piosanguinolenta, optou-se pela lavagem da cavidade torácica com solução salina estéril $(20 \mathrm{~mL} / \mathrm{kg}$, t.i.d.). A antibioticoterapia, com base em antibiograma, foi modificada para a associação de amoxicilina com clavulanato de potássio $(20 \mathrm{mg} / \mathrm{kg}$, b.i.d., s.c.) e ciprofloxacino $(15 \mathrm{mg} / \mathrm{kg}$,b.i.d., i.v.), até a remissão da infecção, totalizando 14 dias de administração.

Arq. Bras. Med. Vet. Zootec., v.68, n.3, p.667-672, 2016
Como o flape de músculo reto abdominal não alcançou o defeito em seu aspecto mais dorsal, ocorreu pneumotórax aberto a partir de curto segmento de deiscência da ferida cutânea de acesso, aos três dias de pós-operatório. Assim, foi ainda necessário comprimir temporariamente a ferida torácica do hemitórax envolvido com compressa cirúrgica estéril, enrolada e fixada sob tensão por suturas cutâneas com fio cirúrgico náilon 1 (Fig. 2A), associando-se essa manobra com o fechamento do ponto de deiscência. A 
compressa foi removida aos oito dias de pósoperatório, e o dreno intratorácico aos 10 dias, quando da redução na produção de efusão pleural para $2 \mathrm{~mL}$ a cada oito horas. $\mathrm{O}$ cão recebeu alta hospitalar aos 14 dias de pós-operatório, por ocasião da remoção de suturas e da cicatrização completa (Fig. 2B).

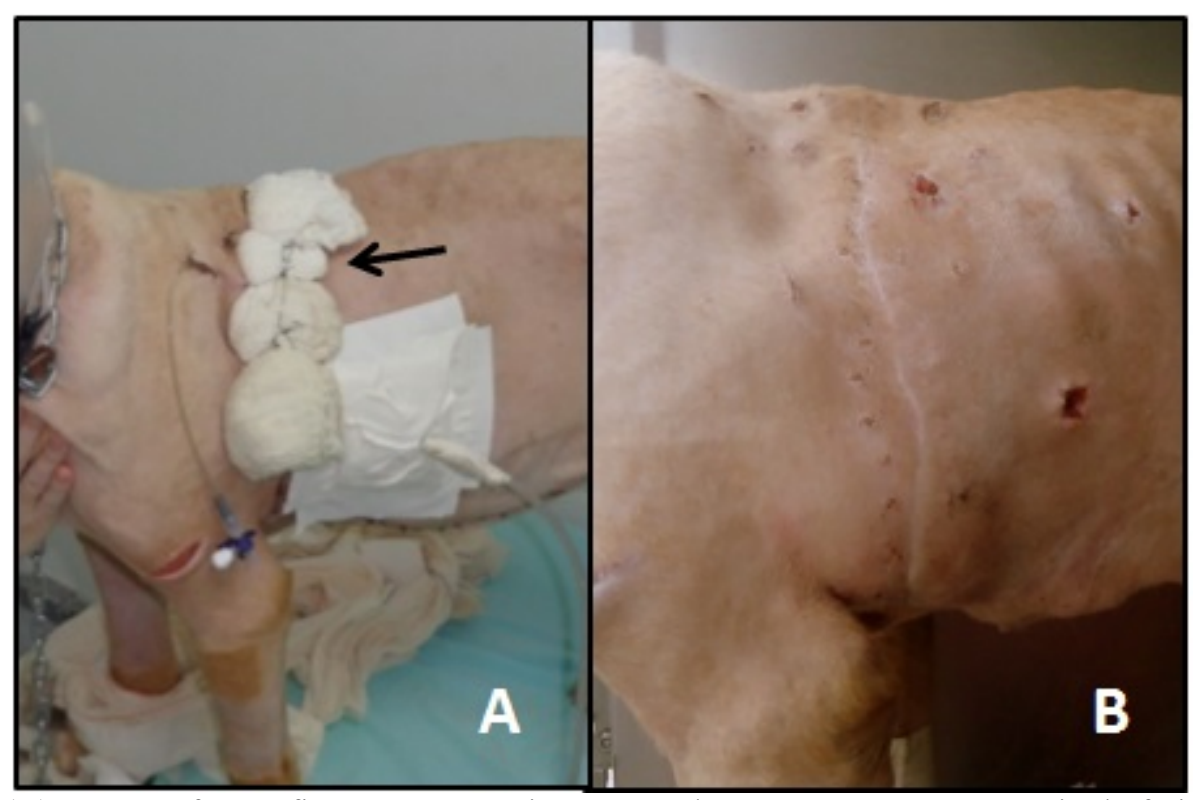

Figura 2. (A) Imagem fotográfica pós-operatória, mostrando a compressão temporária da ferida torácica de acesso com compressa cirúrgica (seta), enrolada e fixada sob tensão sobre ela. (B) Imagem fotográfica da ferida de acesso após cicatrização, por ocasião da alta do cão.

\section{DISCUSSÃO}

As feridas transtorácicas por mordedura resultam na combinação de lesão por perfuração, esmagamento, laceração e avulsão (Shamir et al., 2002). Na maioria dos cães, há graves danos à parede torácica, podendo resultar em extensas áreas de desvitalização dos tecidos subjacentes, pneumotórax, fratura de costelas e lesões a órgãos intratorácicos (Shahar et al., 1997). O paciente deste relato apresentava laceração na região lateral da parede torácica, contínua com espaço pleural, pneumotórax aberto e extensa desvitalização dos tecidos adjacentes à lesão, motivo pelo qual se fez necessário realizar técnica reconstrutiva para o reparo do defeito.

Todas as feridas por mordeduras são altamente contaminadas e, se não tratadas, podem resultar em infecção (Shamir et al., 2002; Scheepens et al., 2006). Amplas áreas de tecido desvitalizado, isquemia e espaço morto abaixo da pele fornecem um meio para o crescimento de bactérias inoculadas (Shamir et al., 2002). A exploração cirúrgica de feridas torácicas penetrantes causadas por mordidas deve ser direcionada ao restabelecimento da integridade do espaço pleural para manutenção da pressão negativa e ao desbridamento completo de todos os tecidos moles desvitalizados na área lesada, a fim de evitar ou controlar a infecção (Shahar et al., 1997; Scheepens et al., 2006; Hunt, 2012).

Quantidades crescentes de drenagem pleural purulenta, ou deterioração clínica, podem requerer nova intervenção cirúrgica para avaliar a necessidade de desbridamento adicional (Shahar et al., 1997). No caso em questão, houve a necessidade de duas reintervenções após a cirurgia inicialmente realizada, para desbridamento adicional, dada a deiscência no plano muscular e o extravasamento de efusão pleural para o subcutâneo. Segundo Scheepens et al. (2006), há significativa associação entre complicações pós-operatórias da ferida e taxas de mortalidade, portanto devem-se evitar desbridamentos incompletos a fim de se preservarem tecidos para a oclusão da ferida. No presente caso, a necessidade de reintervenção foi diretamente associada à infecção patente e, 
possivelmente também, à tensão existente sobre as suturas na parede torácica.

Quando o desbridamento resulta em extensos defeitos dos tecidos moles e o tecido muscular restante é insuficiente para permitir a sutura primária, retalhos musculares ou o omento maior podem ser mobilizados para vedar os espaços intercostais e ocluir a ferida (Shahar et al., 1997; Orton, 2007; Hunt, 2012). O uso de materiais protéticos não está indicado, pois estes requerem rigorosas condições assépticas no momento de implantação, situação difícil de se obter em feridas por mordeduras (Shahar et al., 1997) como no presente caso.

Segundo Kulahci et al. (2011) e Tukiainen (2013), os retalhos pediculados musculares ou musculocutâneos regionais são a primeira escolha para a cobertura de tecido mole dos defeitos da parede torácica em humanos. Retalhos musculares são capazes de contribuir com circulação adicional para áreas de isquemia provocadas por traumatismo, facilitar o retorno da função, melhorar $\mathrm{o}$ aspecto cosmético e reduzir a contaminação e sepse nas feridas (MacPhail, 2014). Para ser adequado como flape, o músculo deve ter espessura apropriada, fácil mobilização, capacidade de rotação local para cobrir o defeito torácico com o mínimo de tensão e uma função que possa ser substituída por outros músculos (Hunt, 2012). Frente a essas características, na terceira intervenção vislumbrou-se o uso do músculo reto abdominal.

$\mathrm{Na}$ medicina, os principais flapes musculares ou musculocutâneos selecionados para a reconstrução de defeitos da parede torácica baseiam-se nos músculos grande dorsal, reto abdominal, peitoral, serrátil e oblíquo abdominal externo (Skoracki e Chang, 2006; Tukiainen, 2013). Músculos recrutados como flapes para ocluir defeitos da parede torácica de pequenos animais incluem o grande dorsal, o oblíquo abdominal externo, o transverso abdominal e o diafragma (Orton, 2007; Hunt, 2012). No caso em questão, optou-se pelo uso de um flape unipediculado de músculo reto abdominal, dada a inviabilidade do emprego de outros retalhos musculares locais, em sua maior parte removidos devido à infecção e à necrose.

O músculo reto abdominal, por sua versatilidade, resistência, grande arco de rotação e mínima morbidade do sítio doador, tem sido amplamente utilizado na cirurgia reconstrutiva humana como retalho muscular ou miocutâneo pediculado (Kulahci et al., 2011) e na transferência de tecido livre com anastomose microvascular (Miller et al., 2007). Em cães, o retalho do músculo reto abdominal foi usado com sucesso para reconstruir defeitos da uretra, da vesícula urinária, da extremidade distal de membros e da cavidade oral (Miller et al., 2007), na correção de hérnia pré-púbica (Archipow e Lanz, 2011) e na reconstrução de defeitos diafragmáticos (Faria et al., 2000). No entanto, não foram encontrados, por estes autores, relatos de seu uso para o reparo de defeitos na parede torácica em cães, advogando quanto ao ineditismo da técnica aqui proposta.

A morbidade pós-cirúrgica no local doador em humanos está associada à formação de seroma, à infecção da ferida cirúrgica, à deiscência e à hérnia da parede abdominal em até $15 \%$ dos casos (Miller et al., 2007; Kulahci et al., 2011). Miller et al. (2007) e Archipow e Lanz (2011) relataram apenas alterações leves e autolimitantes no local doador de cães, como seroma e infecção da ferida cirúrgica. No presente caso, não foram observadas quaisquer alterações no sítio doador.

A oclusão temporária da ferida de acesso com compressa enrolada e fixada sob tensão por suturas cutâneas, técnica previamente utilizada na cirurgia reconstrutiva para estiramento cutâneo, foi considerada eficiente, pois evitou a necessidade de reparo cirúrgico da deiscência na ferida de acesso para a correção do pneumotórax constatado no pós-operatório. Segundo Orton (2007), quando o defeito é demasiado grande para fechamento completo por flape muscular, o omento maior pode ser isolado e mobilizado a partir do abdome para ampliar a cobertura da ferida. Assim, os autores do presente relato acreditam que outra possibilidade consiste no uso combinado de epiplon ao flape muscular em defeitos torácicos extensos.

Na presença ou recorrência de infecção da ferida ou em sinais de declínio na condição do paciente, pode se tornar necessário modificar o protocolo medicamentoso, recomendando-se cultura e antibiograma de amostras da ferida para selecionar os antimicrobianos apropriados (Scheepens et al., 2006). No presente caso, houve necessidade de modificar o protocolo de 
antibioticoterapia adotado inicialmente, dada a presença de infecção não responsiva. Posteriormente, e ainda que pouco tardio, o protocolo adotado com base na cultura e no antibiograma demonstrou-se adequado e houve remissão da infecção, ressaltando-se a importância da escolha do antibiótico baseada no antibiograma.

Devido à produção de efusão pleural piosanguinolenta em volumes crescentes, optouse por realizar lavado pleural, conforme indicado por Orton (2007). Tal procedimento foi realizado durante oito dias e, associado à antibioticoterapia, foi considerado essencial para resolução do grave piotórax apresentado.

\section{CONCLUSÃO}

O flape de músculo reto abdominal demonstra-se como alternativa viável no reparo de defeito extenso da parede torácica de cães, tornando-se uma opção quando os músculos locais não estão disponíveis para reconstrução.

\section{REFERÊNCIAS}

ARCHIPOW, W.; LANZ, O.I. Rectus abdominis muscle flap for repair of prepubic tendon rupture in 8 dogs. Can. Vet. J., v.52, p.1215-1218, 2011.

FARIA, R.X.; PIPPI, N.L.; OLIVEIRA, L.O. et al. Transposição do músculo reto do abdome para correção de defeito iatrogênico no diafragma em cães. Ciênc. Rural. v.30, p.645649, 2000.

HUNT, G.B. Thoracic Wall. In: TOBIAS, K.M; JOHNSTON, S.A. Veterinary surgery: small animal. St. Louis: Elsevier, 2012. p.1779-1786.
KULAHCI, Y; SEVER; C.; EVINC, R. et al. Versatile use of rectus abdominis muscle and musculocutaneous flaps for soft-tissue reconstruction: Our clinical experiences in 25 cases. Eur. J. Plast. Surg., v.34, p.437-444, 2011.

MACPHAIL, C.M. Cirurgia do sistema tegumentar. In: FOSSUM, T.W. Cirurgia de pequenos animais. 4.ed. Rio de Janeiro: Elsevier, 2014. p.245-250.

MILLER, J.M.; LANZ, O.I.; DEGNER, D.A. Rectus abdominis free muscle flap for reconstruction in nine dogs. Vet. Surg., v.36, p.259-265, 2007.

ORTON, E.C. Parede torácica. In: SLATTER, D. Manual de cirurgia de pequenos animais. $3 \mathrm{ed}$. Barueri: Manole, 2007. V.1, p.381-386.

SCHEEPENS, E.T.F.; PEETERS, M.E.; L'EPLATTENIER, H.F.; KIRPENSTEIJN, J.

Thoracic bite trauma in dogs: a comparison of clinical and radiological parameters with surgical results. J. Small Anim. Pract., v.47, p.721726, 2006.

SHAHAR, R.; SHAMIR, M.; OHNSTON, D.E. A Technique for management of bite wounds of the thoracic wall in small dogs. Vet. Surg., v.26, p.45-50, 1997.

SHAMIR, M.H.; LEISNER, S., KLEMENT, E. et al. Dog bite wounds in dogs and cats; a retrospective study of 196 cases. J. Vet. Med. Ser., v.49, p.107-112, 2002.

SKORACKI, R.J.; CHAN, D.W.; CHANG, D.W. Reconstruction of the chest wall and thorax. J. Surg. Oncol., v.94, p.455-465, 2006.

TUKIAINEN, E. Chest wall reconstruction after oncological resections. Scand. J. Surg., v.102, p.9-13, 2013. 